\title{
CAMBIOS EN EL CONCEPTO DE LA OPINIÓN PÚBLICA A FINES DEL SIGLO XVIII
}

En los años veinte del siglo xvilı las opiniones compartidas por mucha gente, o generalizadas, no le inspiraban gran confianza al padre Feijoo, y más bien le parecían sospechosas. "El valor de las opiniones se ha de computar por el peso, no por el número de las almas', decía en su ensayo Voz del pueblo. Encontraba dudoso el juicio de la mayoría tanto en la política como en la moral. Y si algunas veces acertaba, era "por ajena luz o por casualidad"'.

Un siglo más tarde el mismo recelo de la ignorancia y el error se expresaba a veces, pero la opinión mayoritaria - sobre todo en la política- merecía más respeto y, a veces, hasta veneración. En 1820, a juzgar por Pérez de Camino, la benéfica fuerza de la opinión pública resultaba admirable. La opinión podía destronar tiranos, restablecer el régimen legal y democrático ("el imperio de la ley"), y expresarse libremente. En el caso específico del despotismo napoleónico, de reciente fecha, fue "el torrente de la opinión" lo que le había arrollado, dejando que continuara en su lugar la marcha de la civilización en Europa ${ }^{2}$.

Entre Feijoo y Pérez de Camino se produjo un cambio importante de ideas con respecto a la opinión en el terreno de la política. Nace por entonces, al parecer, el concepto de la opinión pública en el sentido moderno, en la misma época en que se establecía en España la idea de la soberanía del pueblo y se rechazaba el absolutismo. Antes los reyes habían tenido que vigilar las actitudes de sus pueblos en épocas de crisis, y se había reconocido la importancia de su punto de vista en algún momento en el siglo XVII ${ }^{3}$. Pero la idea de que la opinión pública podría y debería reflejarse en las acciones y posturas del gobierno sólo se impuso

1 Véase FeIjoo, Teatro crítico universal, sel., pról. y notas de Agustín Millares Cario, Espasa-Calpe, Madrid, 1958, t. 1, pp. 85-86.

${ }^{2}$ La opinión. Poema, con un discurso preliminar y notas; por $D^{n} M . N$. Pr de Camino, Burdeos, 1820, pp. 8-9, 47.

3 Refiriéndose a las revoluciones de Inglaterra en 1649, el conde de Peñaranda comenta en una carta al rey "la resolución con que [el pueblo] se hace justicia a sí mismo, trayendo a la memoria que es el pueblo quien introdujo y dio autoridad a los Reyes para su defensa y conservación, y si abusa de esta autoridad se la podrá quitar quien se la dio" (Bruselas, el 4 de marzo de 1649, Archivo General de Simancas, Estado, 
en España a fines del siglo xviII. Cuando más estuvo en auge fue durante la Guerra de la Independencia. Los cambios semánticos de la palabra "opinión", que se advierten ya en los años noventa del siglo XVIII, se establecen plenamente entonces, subrayando su rápido desarrollo. Aunque no figura dicha expresión en el análisis fundamental de El primer lenguaje constitucional español de María Cruz Seoane, aparece en efecto en alguno de los textos citados por esta autora, y se relaciona estrechamente con el concepto de una voluntad general de tipo crítico registrado por ella en los periódicos de la época ${ }^{4}$. En un estudio posterior, María Cruz Seoane ha destacado la opinión pública como una de las ideas clave en el periodismo de principios del siglo pasado ${ }^{5}$. En efecto, los autores del Semanario patriótico señalaban su primacía, invocando a la opinión pública en su prospecto. Allí se exageraba quizá la influencia de la opinión en la caída de Godoy y en la reacción del pueblo frente a la invasión francesa. Pero es evidente que los redactores - Manuel Quintana y Eugenio de Tapia- reconocían la potencia latente de un espíritu público para la unidad del país y trataron de fomentar la opinión. En realidad, todos los partidos procuraban manipular la opinión pública durante la guerra, como es inevitable. No extraña por lo tanto que viniera a ser una de las principales directrices de la política constitucional española, ya que inspiraba tanto respeto a todos. Los primeros párrafos del prospecto del Semanario patriótico reflejan este respeto muy claramente:

La opinión pública es mucho más fuerte que la autoridad malquista y los exércitos armados. Ésta es la que ha hecho nacer las circunstancias extraordinarias en que nos vemos los Españoles: la que derribó al Favorito insolente que por veinte años estuvo insultando a la Nación, la que puso en el trono a un Príncipe idolatrado del pueblo que veía en él un compañero de su opresión, y el árbol de su esperanza; y la que ha producido prodigios de valor, que con espanto y admiración de Europa acaban de obrar nuestras Provincias. La opinión es la que coronará nuestros esfuerzos con la independencia y la soberanía que íbamos a perder, y ella en fin consolidará nuestra fortuna con una organización interior, que nos ponga a cubierto por mucho tiempo de los males que hemos sufrido.

Es pues de absoluta necesidad dar a este resorte moral quanta elasticidad sea posible, y para ello no hay mejores medios que los que proporciona la imprenta en los papeles periódicos; destinados por su naturaleza a excitar, sostener y guiar la opinión pública. Así lo han conocido las Provincias de España, en cuyas capitales luego que se formó la resolución ge-

Leg. 2070). Citado en Colección de documentos inéditos para la historia de España . . , Madrid, 1885, tomo 83, p. 365. Peñaranda parece querer advertir al rey que es necesario atraerse la opinión pública: ser amado lo mismo que ser temido.

4 Véase El primer lenguaje constitucional español, Madrid, 1968, p. 145 (citando a El Duende, núm. 2), y las observaciones acerca de la "voluntad general" en las pp. 89-90, y sobre el "espíritu público" en las pp. 141-142.

${ }^{5}$ La importancia del concepto de opinión pública la desarrolla MARÍA CRUZ SEOAne en Historia del periodismo español. 2. El siglo xix, Madrid, 1983, pp. 28 ss. 
nerosa de sacudir el yugo abominable que se nos quería imponer, al instante salieron Gazetas y Diarios para exaltar el patriotismo, y comunicar luces y noticias ${ }^{6}$.

La acepción que tiene la expresión “opinión pública” en 1808 y 1809 es, como ya hemos sugerido, relativamente nueva. Ya que va tan unida al desarrollo de un nuevo concepto del papel del pueblo en el sistema de gobierno en España, vale la pena precisar cómo y cuándo adquiere un sentido novel.

Existe, desde luego, el término "opinión pública" en los años setenta y ochenta del siglo XVIII, y es posible que se pueda rastrear antes. Pero su sentido entonces es otro. En aquella época se relaciona con el pundonor, y significa la buena o mala fama, la reputación o estimación en el concepto de las gentes, que un individuo tiene. Bajo este signo lo usa Nicolás Fernández de Moratín en su tragedia Lucrecia, y también Jovellanos, con fecha posterior, en El delincuente honrado. En la obra de Moratín padre se refiere Bruto a los nobles del ejército "que el nombre augusto y la opinión romana / sostienen, a morir apercibidos"'. En la cuarta escena del Acto III, el cielo cuidará "de sostener indemne la libertad y la opinión romana", realzando de nuevo la idea de reputación con esta palabra ${ }^{7}$. En El delincuente honrado Torcuato y Simón discuten acerca de la ley y los desafíos en la quinta escena del Acto I. Torcuato lamenta el hecho de que no concuerden las leyes con las costumbres nacionales (refiriéndose a la falta de estudios sobre el "espíritu de nuestras leyes" y pensando, como está bien claro, en Montesquieu). Una persona retada por otra no puede aceptar el desafío según la ley, y sin embargo será despreciada como cobarde por la sociedad si se niega a luchar. En el caso de que rechace el desafío, "¿quedará su honor bien puesto?", pregunta Torcuato. "El honor, señor," continúa, "es un bien que todos debemos conservar; pero es un bien que no está en nuestra mano, sino en la estimación de los demás. La opinión pública le da y le quita". No muy distinto es el uso que hace de la misma frase Josefa Amar y Borbón en su Discurso sobre la educación física y moral de las mugeres. La emplea esta admirable autora en un pasaje donde alude a los problemas de las solteras. Por poco libres que sean estas últimas en su comportamiento, se las criticará. "Aun quando se halle [la soltera]" , afirma doña Josefa, "en edad de que prudentemente puede valerse de su libertad sin perjuicio de sus costumbres, la opinión pública, que es más poderosa que todas las razones, la mira siempre como una persona a quien no le está bien hacer lo que a las casadas y a las viudas" 9 .

6 Semanario patriótico, Imprenta de Repullés, Madrid, 1808, t. 1. Prospecto.

7 Véase Teatro español del siglo xviii. Antologia, ed. Jerry L. Johnson, Bruguera, Barcelona, 1972, pp. 390 y 396. La tragedia fue estrenada en 1763.

8 Ibid., 764. La comedia se escribió por los años de 1773-1774.

9 JOSEFA AMAR Y BORBÓN, Discurso sobre la educación física y moral de las mugeres, Madrid, 1790 , p. 265. Debo esta cita a la amabilidad de mi amiga Nicole Harrison. 
En los años noventa del siglo XviII aparecen las primeras referencias que hemos encontrado hasta ahora a una idea nueva de la opinión pública en autores políticos como el conde de Cabarrús, León de Arroyal, Jovellanos y Juan Pablo Forner. No todos ellos emplean las mismas palabras, pero es evidente que la opinión influye ya en la vida política y no sólo en la vida social. Es más, el interés por la opinión pública entonces corresponde a una creciente preocupación por la participación de la comunidad en los procesos gubernamentales. Los políticos se muestran cada vez más sensibles a la opinión de la sociedad y también creen que hay que movilizarla a favor de sus programas. Los ministros ilustrados se fían de los avances de la enseñanza y suponen que la razón triunfará al fin y al cabo. Tras esto se podrá llegar a un acuerdo racional aceptado por un pueblo instruido respecto a la nueva legislación que se planea o a los proyectos ideados con el fin de mejorar el país.

Nuestro primer ejemplo de este uso data de 1794. El 3 de septiembre de este año, Jovellanos emplea las palabras “opinión pública" en su Diario en un contexto y con un sentido distintos de los antes encontrados en su comedia lacrimosa El delincuente honrado. Se refiere Jovellanos esta vez a su correspondencia con Jardines, amigo de reconocida tendencia radical, y expresa su confianza de que no se altere la seguridad pública de España, donde no esperaría que se produzcan desórdenes como los ocurridos en Francia, donde se acaba de anunciar la muerte de Robespierre. Afirma Jovellanos su voluntad de buscar el progreso en su país en la medida que lo permita la masa de la gente, desechando los métodos violentos y revolucionarios. "No hay más medio", asevera, "que mejorar la opinión pública por los medios que ella permita; lo demás, es causar la desolación de los mismos a quienes se quiere consolar'"10.

Un año más tarde el conde de Cabarrús también reconoce la importancia de la opinión en cuestiones políticas. Afirma que el fracaso de la política ha sido siempre la consecuencia de una falta de apoyo general para las ideas de una minoría: "La destrucción de las sociedades políticas, o la anarquía más o menos completa de todas ellas", dice, "nace [... ] de haber usurpado el interés particular la expresión de la voluntad común"'11. Esta voluntad común se expresaría por alguna manifestación de la opinión pública, pero Cabarrús no emplea este término -o por lo menos no hemos encontrado ningún pasaje en que lo emplee. Es muy consciente, sin embargo, de los efectos de la opinión y dedica una de sus Cartas a Jovellanos a los obstáculos que dicha opinión opone a la felicidad de la nación. En su Carta segunda se refiere más de una vez a "la razón pública", a la "voluntad y el interés gene-

10 Gaspar Melchor de Jovellanos, Diarios, sel. de Julián Marías, Madrid, 1967, pp. 127-128.

11 Cartas sobre los obstáculos que la naturaleza, la opinión y las leyes oponen a la felicidad pública, escritas por el conde de Cabarrús, $3^{\mathrm{a}}$ ed., Madrid, 1820, p. 9. 
ral o común", incluso a la "opinión recíproca" y a las "opiniones respectivas al gobierno" 12 . Estas expresiones parecen implicar el concepto de opinión pública en el nuevo sentido, a pesar de que Cabarrús no haya empleado este término, que sepamos.

No es muy diferente la situación de León de Arroyal, cuyas Cartas económico-políticas son más o menos de la misma época que las del conde. Arroyal es uno de los grandes partidarios de una constitución que encarnara la idea de la voluntad general: "el consentimiento del reino" para proteger el "interés común" contra "el interés particular"13. Las cartas de Arroyal resultan fuertemente anti-jerárquicas en algunos lugares y es evidente que su autor se daba cuenta de su carácter provocador y hasta revolucionario ${ }^{14}$. El concepto de opinión pública está latente en la obra y, sin embargo, no se encuentra el término explícitamente en ella.

Comparable al conde de Cabarrús y a León de Arroyal es el Jovellanos del Informe sobre la ley agraria. En el Informe la opinión general es a veces obstáculo que hay que vencer: la opinión, por ejemplo, adversa a la idea fisiocrática de que los progresos de la agricultura produzcan los efectos más importantes para la economía nacional. Otras veces es la opinión equivocada a la que habría que convencer de su error. $\mathrm{Y}$, sin embargo, en los dos casos la opinión -llamada "opinión del público" en los párrafos 244 y 245 - influye sobre la política. En los discursos de Jovellanos en los años ochenta y noventa no aparece la frase "opinión pública" aun cuando en el que leyó en su recepción a la Real Academia de la Historia (el 4 de febrero de 1780), sí emplea las expresiones "voluntad general" y "modo de pensar de una nación"15. Asevera que la gente no se atreve a "descubrir sus opiniones en las materias del gobierno", pero él mismo quiere ser "el órgano de los deseos públicos"16. Late la idea de la opinión pública en este discurso a pesar de que no se emplee el término. En su oración "Sobre la necesidad de unir el estudio de la literatura al de las ciencias", en cambio, leída en abril de 1797 en el Real Instituto Asturiano, reconoce las exigencias de la opinión pública y la necesidad de captarla en el segundo párrafo. Y en este caso no deja de emplear la expresión ${ }^{17}$.

En Forner también se encuentran el concepto y las palabras mismas en el Discurso sobre el amor de la patria que fue pronunciado en una junta celebrada por la sociedad patriótica de Sevilla en 1794. En esta obra Forner afirmó tajantemente que "las opiniones públicas y genera-

12 Ibid., pp. 96, 97, 100, 102-103, 105 y 112.

13 León de Arroyal, Cartas económico-políticas, ed., pról. y notas de José Caso González, Oviedo, 1971, pp. 177-253.

14 Véase la ed. cit., p. 244.

15 Gaspar Melchor de Jovellanos, Obras en prosa, ed. José Caso González, Clásicos Castalia, Madrid, 1970 , pp. 78 y 80.

16 Ibid., pp. 91 y 101.

17 Ibid., p. 206. 
les hacen felices o infelices a las naciones" ${ }^{18}$. Pero el trasfondo del término en este pasaje es más bien económico o social que político. Emplea la palabra “opinión" en el contexto de las ideas recibidas sobre determinadas cosas, y en un pasaje donde se trata más que nada de la reputación o estimación que se forma de las personas según los empleos que tienen. Se puede equiparar este sentido al que se halla en la comedia lacrimosa de Jovellanos y la tragedia de Moratín, y se refiere al desdén que se solía sentir en España hacia el comerciante, el artesano y el labrador. Aludiendo al problema del poco aprecio en que las artes y oficios se tenían en las más de las provincias españolas, y a las malas consecuencias económicas de la opinión pública con respecto a esto, Forner se hace eco de Campomanes y del Discurso sobre el fomento de la industria popular (Madrid, 1774) ${ }^{19}$.

Contemporánea con la referencia a la opinión pública en los Diarios de Jovellanos hay otra con idéntico sentido en un escrito (en francés) de un refugiado. Se trata de una memoria al rey de España redactada por un padre dominico, titulada Projet d'utilité publique y fechada en Madrid el 27 de noviembre de 1794. En este escrito el dominico emplea la frase "opinion publique" más de una vez, y afirma la necesidad de estimular la opinión pública para tratar de evitar en España las funestas consecuencias de las ideas revolucionarias al estilo francés: ideas que, por otra parte, se discutían abiertamente en las calles de Madrid. Una de las propuestas del dominico es la creación por parte del gobierno español de un periódico destinado a realzar las ventajas de la monarquía. "Tal periódico", asevera, "¿no podría tener una influencia feliz sobre la opinión pública y no sería útil para la sociedad civil desde el punto de vista de la religión y de la política?' '20 Este proyecto, de haberse llevado a cabo, se hubiera adelantado en más de diez años al Semanario patriótico en cuanto al móvil de modificar y unificar las opiniones del pueblo español. En la Memoria redactada por el mismo padre para acompañar el proyecto, se vuelve a insistir sobre la importancia de la opinión pública. "Malhaya el gobierno", dice, "que emplea tan sólo la fuerza y no cuenta con la opinión pública" ("Malheur à toute administration qui, ne comptant que sur la force, négligeroit l'opinion publique") ${ }^{21}$.

En cuanto a los españoles mismos que emplean la palabra "opinión", en los años noventa del siglo xvill merece destacarse el caso de Nicasio Álvarez de Cienfuegos. Parece importante el concepto de la opinión pública para la política en su tragedia La condesa de Castilla. Y no obstante, la frase "opinión del pueblo", que encontramos en aquella obra, es ambigua. Sancho, en la escena cuarta del Acto I, lamenta el poder que disfruta la condesa, y lo atribuye en parte al apoyo del pueblo. "La con-

18 Obras de Don Juan Pablo Forner recogidas y ordenadas por Don Luis Villanueva, Madrid, 1844, p. 228.

19 Ibid., pp. Ixviii-lxix.

20 A.H.N, Estado, Leg. 3022, núm. 16, p. 24.

21 Ibid., núm. 16. 
desa, a mandar acostumbrada," dice, "tiene el cariño y la opinión del pueblo" "22. Aquí la frase parece referirse a la buena opinión que se tiene de las cualidades de la condesa. Y en este caso el término seguiría reflejando la estimación o la fama del individuo. Pero no es imposible interpretarla de una manera distinta ya que Cienfuegos insiste en esta tragedia en el importante papel del pueblo en una monarquía. No sería inverosímil, por lo tanto, que la frase se refiriera al apoyo socio-político de la gente, y no sólo a su aprobación moral.

Como ya hemos señalado, la opinión pública llegó a tener una importancia especial durante la Guerra de la Independencia, tratándose de un nuevo factor que se debía tener muy en cuenta entonces. Sabemos que los ingleses querían indagar la opinión pública de los españoles en Madrid bajo el dominio de los franceses. Y en las Cortes de Cádiz se arguyó a favor de la libertad de imprenta, porque se creía que la expresión de la opinión pública favorecería la unidad y la paz. Uno de los diputados, Muñoz Torrero, creyó que el público debía de tener oportunidades para criticar abiertamente a sus representantes. "El pueblo español ha detestado siempre las guerras civiles", afirma, "pero quizá tendría desgraciadamente que venir a ellas. El modo de evitarlo es permitir la solemne manifestación de la opinión pública. Todavía ignoramos el poder inmenso de una nación para obligar a los que gobiernan a ser justos. Empero prívase al pueblo de la libertad de hablar y escribir: ¿cómo ha de manifestar su opinión?'”23

Durante la guerra, Quintana - cuya capacidad para animar al lector se reconocía universalmente - fue invitado por los partidarios del rey José lo mismo que por la Junta a poner su inspirada prosa al servicio de sus respectivas causas. "Nadie ignora cuánto obra la opinión en las crisis políticas', decía ${ }^{24}$. Sabía perfectamente la importancia de conseguir el apoyo del pueblo para las iniciativas políticas. Trató de "preparar" la opinión pública y parece haber reconocido la novedad del término. Empleó las palabras en la segunda redacción de su Proyecto de reforma (octubre de 1809), aunque no en la primera versión. En un principio se le ocurrió referirse a ciertas publicaciones destinadas a "conservar y mantener el espíritu público de independencia, lealtad, valor y patriotismo" 25 . Luego, más escuetamente, se alude al objeto de "sostener la opinión pública" 26.

Después de la guerra Quintana atribuyó la fortuna de sus Poesías patrióticas al hecho de que "los sentimientos y principios bajo los que fueron concebidas estaban en armonía con los sentimientos y opinión

22 Poesias de Don Nicasio Álvarez de Cienfuegos, Ildefonso Mompié, Valencia, 1816, "La condesa de Castilla", p. 20

23 Véase Lecciones españolas de elocuencia y moral, Barcelona, 1839, p. 86

24 Quintana revolucionario, ed. M. E. Martínez Quinteiro, Madrid, 1972, p. 50.

25 Véase Albert Dérozier, Manuel Josef Quintana et la naissance du libéralisme en Es. pagne, Paris, 1970 , t. 2, p. 256.

26 Ibid., p. 257. 
del público en los grandes intereses de la patria"'27. Por entonces estaba seguro de que existía un "espíritu general" que guiaba la nación, y lamentaba la escasez de medios por los que la opinión pública podía expresarse ${ }^{28}$.

La misma incertidumbre con respecto al término apropiado se encuentra en el Examen de los delitos de infidelidad a la patria, imputados a los españoles sometidos bajo la dominación francesa, publicado anónimamente en Auch, Francia, en 1816, pero escrito dos años antes por Félix José Reinoso. En el capítulo XIX de este libro se alude indistintamente al "es" píritu público", "la opinión general del reyno", "la opinión del pueblo" y "la opinión pública". El ministro afrancesado e historiador de la Inquisición, Juan Antonio Llorente, empleó la frase "opinión nacional" cuando quiso indagar la actitud más común entre los españoles sobre la Guerra de la Independencia. Redactó su ensayo en Valencia en septiembre de 1812, y fue publicado en Zaragoza el año siguiente. La Inquisición lo condenó en 1815. Llorente tituló el ensayo Discurso sobre la opinión nacional de España acerca de la guerra con Francia, y suponía que esta opinión nacional o pública estaría casi totalmente en contra de la guerra y a favor de la paz.

Es esta confianza en la opinión pública y en el concepto mismo lo que Pérez de Camino celebra en un poema con discurso preliminar y rotas extensas titulado precisamente La opinión. Publicado en Burdeos en 1820 , pero escrito en gran parte antes de la revolución constitucional de aquel año en España, el poema esboza la historia de la opinión desde los conflictos políticos del pasado entre el pueblo y los reyes y magnates, hasta las revoluciones y movimientos constitucionales de su época. Pérez de Camino no era partidario de la Revolución francesa, aunque admiraba los beneficios que trajo consigo para otros países europeos. Su ideal es la tolerancia y el acuerdo tanto en las materias políticas como en las religiosas, y cree que esta tolerancia es asequible en una época en que las opiniones pueden publicarse sin miedo a la censura, gracias a la libertad de imprenta. Expresa, como antes Quintana en su Oda a la invención de la imprenta, su fe en las letras de molde como medio de difundir la libertad. En esta obra no figura para nada la antigua idea de la opinión como reputación personal, ni la desconfianza con respecto a las ideas generalizadas tan frecuente en los autores de las generaciones anteriores.

\section{Nigel Glendinning}

Queen Mary College, London.

27 Quintana revolucionario, ed. cit., p. 56.

28 Ibid., pp. 58 y 47. 